СОВРЕМЕННЫЕ ПОДХОДЫ В ФОРМИРОВАНИИ ВОКАЛЬНОИСПОЛНИТЕЛЬСКОЙ КУЛЬТУРЫ СТУДЕНТОВ В ВУЗЕ

\begin{abstract}
Чжу Тяньи
Федеральное государственное бюджетное образовательное учреждение высшего образования «Российский государственный педагогический университет им. А.И. Гериена», Санкт-Петербург, е-таil: 734868930@qq.com Образование является важной и ключевой ступенью для успешной творческой деятельности. Уровень и качество образования в большинстве случаев коррелируют с профессионализмом выпускников. В статье рассматривается современное состояние российского вузовского вокального образования в контексте формирования вокально-исполнительской культуры будущих специалистов, анализируются теоретические работы на эту тему. Кроме того, автором изучены учебные планы рабочих программ оперного пения Санкт-Петербургской государственной консерватории им. Н.А. Римского-Корсакова и Московской государственной консерватории им. П.И. Чайковского. В результате сделаны выводы о значительной эффективности компетентностного и интеграционного подходов в учебном процессе вокального класса как методологических инструментов не только овладения студентами профессиональными знаниями и навыками пения, но и формирования вокально-исполнительской культуры как ключевой компетенции будущих специалистов. Однако учебный план специалитета российских вокальных вузов может быть доработан с учетом адаптации обучения азиатских студентов. Кроме того, в отличие от европейских учебных стандартов бакалавриата, российские рассчитаны на широкое и разнообразное образование и не ориентированы в достаточной степени на более узкие специализации, что может быть важно при подготовке профессионалов в определенной области пения.

Ключевые слова: вокальное образование, вокально-исполнительская культура, компетентностный и интеграционный подходы, учебный план, пение.
\end{abstract}

\title{
MODERN APPROACHES IN THE FORMATION OF VOCAL AND PERFORMING CULTURE OF STUDENTS AT THE UNIVERSITY
}

\section{Zhu Tianyi}

Federal State Budgetary Educational Institution of Higher Education «Herzen State Pedagogical University of Russia», Saint Petersburg, e-mail: 734868930@qq.com

Education is an important and key step for successful creative activity. The level and quality of education in most cases correlate with the professionalism of graduates. The article examines the current state of Russian university vocal education in the context of the formation of vocal and performing culture of future specialists, analyzes theoretical works on this topic. In addition, the author studied the curricula of the working programs of opera singing at the St. Petersburg State Conservatory named after N.A. Rimsky-Korsakov and the Tchaikovsky Moscow State Conservatory. As a result, conclusions are drawn about the significant effectiveness of competencebased and integration approaches in the educational process of the vocal class as methodological tools for mastering students not only professional knowledge and singing skills, but also the formation of vocal and performing culture as a key competence of future specialists. However, the curriculum of the specialty of Russian vocal universities can be finalized taking into account the adaptation of the training of Asian students. In addition, unlike European bachelor's degree standards, Russian ones are designed for a wide and diverse education, and are not sufficiently focused on narrower specializations, which may be important when training professionals in a certain field of singing.

Keywords: vocal education, vocal and performing culture, competence and integration approaches, curriculum, singing.

Вопросы соответствия образовательного процесса существующим практикам профессии, в которой будут строить карьерный путь выпускники, волнуют специалистов в разных областях и разных странах. Если образование дает выпускнику соответствующие навыки и компетенции, то он выходит на рынок подготовленным специалистом [1, с. 319], если же нет, то образование можно считать некачественным. Второй момент, который показывает качество образования, - заинтересованность иностранных абитуриентов в 
образовании [2, с. 30] и наличие таких предметов, которые помогут им успешно закончить курс обучения и стать востребованными специалистами в своей стране или стране обучения. С этих двух точек зрения мы проанализируем российское вокальное образование в данной статье.

Цель исследования - показать на примере современных учебных планов двух ведущих консерваторий страны возможности использования компетентностного и интеграционного подходов в формировании вокально-исполнительской культуры студентов.

\section{Материал и методы исследования}

Исследование проведено посредством анализа научно-исследовательских теоретических работ, посвященных современному российскому образованию, изучения рабочих программ вокальных факультетов Санкт-Петербургской государственной консерватории им. Н.А. Римского-Корсакова и Московской государственной консерватории им. П.И. Чайковского 2020 г. (специальность 53.05.04 «Музыкально-театральное искусство», специализация программы: «Искусство оперного пения», уровень специалитета).

\section{Результаты исследования и их обсуждение}

В данной статье мы будем рассматривать актуальные педагогические подходы в современном российском вокальном образовании в формировании вокально-исполнительской культуры студентов, в том числе из других стран. К данной проблематике обращаются многие известные педагоги-вокалисты, в частности Л.Б. Дмитриев, В.А. Багадуров, И.К. Назаренко, Г.П. Стулова и др.

Китайский исследователь Ни Чжэнь, опираясь на концепции российской вокальной школы в этой сфере, отмечает, что сущность определения вокальной культуры заключается в комплексе воспитания певца в рамках музыкальной науки, где уровень культуры является отражением профессионального уровня исполнительской деятельности [3, с. 131]. В свою очередь, А.Г. Сенцова, Л.Л. Полищук говорят о роли личности вокалиста-исполнителя в формировании вокально-исполнительской культуры [4, с. 377-380].

При анализе феномена вокально-исполнительской культуры мы также будем опираться на описание феномена высокой вокально-исполнительской культуры, данное исследовательницей Т.Д. Смелковой, согласно которой этот феномен определяется «совокупностью профессиональных компетенций исполнителей, включающих высокие навыки пения и уровень сценического мастерства, художественную целостность образа, создаваемого вокалистом» $[5$, с. 56].

Таким образом, мы можем охарактеризовать современную вокально-исполнительскую культуру как сочетание национальных культурно-исторических исполнительских традиций с профессиональным уровнем певцов, их личностной интерпретацией произведений. 
Российская вокально-исполнительская культура, в свою очередь, является отражением национальных культурных особенностей в целом и богатого наследия русской оперной традиции. Мировая вокально-исполнительская культура формируется из взаимодействия и интеграции культурных традиций разных стран, исполнительских школ и творческого взаимодействия исполнителей. Так, российская вокально-исполнительская культура влияет на формирование общей мировой вокально-исполнительской культуры, о чем свидетельствует вклад российских оперных вокалистов во всемирно известные оперные постановки.

И наоборот, общая тенденция к интеграции культур разных стран и народов, глобализация, развитие технологий привели к формированию единой, не имеющей границ мировой вокально-исполнительской культуры, где творческий путь вокалиста-исполнителя, как никогда, зависит от выхода его деятельности на международную арену. Таким образом, мировая оперная практика в какой-то мере диктует условия для воспитания и подготовки конкурентноспособных вокалистов. Все это требует определенной корректировки учебного процесса вокального класса, внедрения инновационных педагогических технологий и подходов.

Изменения в мировой исполнительской культуре, связанные с тем, что последние десятилетия существует просветительская тенденция постановок классических произведений, стремление их популяризировать (например, прослеживается влияние массовой культуры на постановки в Большом театре России [6]), разумеется, требуют изменений и в современном образовательном пространстве. Одной из главных целей современного вокального образования становится стремление обеспечить конкурентоспособность и дальнейшее трудоустройство молодого специалиста за счет развития творческого мышления исполнителя в контексте актуализации и модернизации классических произведений оперного жанра.

Современные оперные постановки часто отличают свобода интерпретации сценического текста, перенос времени действия в современный мир, а также новые режиссерские видения, отвечающие актуальным проблемам общества. Новая оперная среда в некотором роде бросает вызов классической подготовке оперных вокалистов, требуя от них все большего уровня владения современной сценической культурой.

Безусловно, в программах обучения академических вокалистов в высших учебных заведениях присутствуют уроки актерского мастерства и сценического искусства. Однако вопросом для дискуссии остается то, насколько сценический опыт, получаемый при обучении, соответствует реальной картине будущей профессиональной деятельности исполнителя [7, с. $10]$.

Стремление к развитию креативного мышления и способность к быстрому поиску и анализу информации, на наш взгляд, являются важными качествами современного вокалиста, 
позволяющими ему «влиться» в современную профессиональную культуру. И именно педагог в первую очередь способствует развитию этих качеств.

Студент во время обучения максимально приближается к пониманию ценностных характеристик вокально-исполнительской культуры. Преподаватель же должен являться не неким «оригиналом», с которого ученик должен создать свою «копию» (к примеру, скопировать стиль исполнения), а проводником-посредником к созданию уникальной индивидуальной творческой личности [7, с. 10]. Еще в конце ХХ в. исследователь Б. Корнетов заметил, что в современной образовательной парадигме педагог и студент становятся «соавторами» [цит. по 8, с. 17], которые объединены единой целью создания произведения искусства.

Однако мы бы хотели подчеркнуть, что педагог не перестает быть примером для подражания для вокалиста. Скорее, в современном подходе к вокальному образованию в рамках общей вокально-исполнительской культуры смещается акцент с полного копирования исполнительского стиля к развитию индивидуальных интерпретационных качеств молодого музыканта.

Следовательно, личный пример педагога-вокалиста в рамках российской вокальной школы также является важнейшей частью формирования вокально-исполнительской культуры. Так, известный педагог-музыкант Л.Г. Арчажникова пишет о том, что именно личный пример педагога-исполнителя формирует культуру будущего вокалиста путем грамотного погружения учащегося в сферу музыкального искусства, совместного с педагогом исполнительского творчества и характеризует педагога как «проводника музыкальной культуры» [9, с. 11].

Именно поэтому современная российская педагогика в том числе обращается к вопросу места личности в пространстве музыкального социума. Так, Е.С. Курдина подчеркивает, что личность становится «источником общественного прогресса как абсолютная ценность» [10, с. 114], причем именно художественное образование, в том числе музыкальное, формирует ее основные качества. И немалую роль в этом играют самостоятельность и целостность личности.

Влияние личности на выполнение профессиональных обязанностей отмечается в разных сферах, связанных с трудоустройством молодого специалиста. В сфере найма сотрудника в любой области существует разделение на hard skills (англ. «жесткие навыки») и soft skills (англ. «мягкие навыки»). Hard skills - это список обязательных измеримых требований, предъявляемых к профессии. Так, для вокалиста примерами «твердых» навыков могут быть умение читать нотный текст, владеть голосовым аппаратом, обладать базовыми навыками аккомпанемента. Навыки «твердые» легко проверяются с помощью экзаменов в 
высших учебных заведениях.

«Мягкие» навыки - это то, без чего сотрудник не сможет влиться в команду, социализироваться, это то, как проявляются личные и психологические качества в рабочей среде. Важность таких навыков была давно отмечена в педагогике, и они получили название «компетенции».

Формирование компетенций специалиста, которые позволят ему стать полноценным участником профессионального сообщества и осуществлять педагогическую и исполнительскую деятельность, подробно рассматривает в своем исследовании А.Э. Федоров. Он характеризует компетентностный подход к обучению как «постепенную переориентацию доминирующей образовательной парадигмы с преимущественной трансляцией знаний, формированием навыков на создание условий для овладения комплексом компетенций» [11, c. 31].

Целью компетентностного подхода, по мнению Н.Н. Ковальчук и Т.Г. Ставер, является создание образовательной среды, где в психологически комфортных условиях (что, на наш взгляд, особенно важно для вокального исполнителя) происходит организация образовательного процесса, отличающегося целостностью, высокой функциональностью и креативностью [12, с. 410].

Исследователь Д.А. Иванов видит в данном подходе создание правильного профессионального предложения (где предложением выступает специалист) с точки зрения спроса на рынке труда [13, с. 21]. В свою очередь, Е.Я. Коган характеризует процесс обретения профессиональных компетенций с точки зрения умения специалиста мыслить комплексно для дальнейшего решения профессиональных задач [14, с. 28-32]. С.А. Останина отмечает, что фокус современной образовательной парадигмы при применении компетентностного подхода смещается от человека «знающего» в сторону человека «подготовленного» к профессиональным трудностям, и к системе знаний добавляется умение решать проблемы в своем профессиональном поле [15, с. 5].

Резюмируя различные позиции по данной проблематике, сошлемся на основополагающий тезис И.А. Зимней, считающей, что компетентностный подход становится одним из основных принципов современной педагогики из-за смены образовательной парадигмы и поиска нового пути постсоветской педагогики, а также желания создать единую «архитектуру» для образования, чтобы оно коррелировало с европейскими и мировыми стандартами [16, с. 10]. В свою очередь добавим - это оптимизирует карьерный путь выпускника в условиях глобализации.

Исследователи А.Э. Федоров, С.Е. Метелев, А.А. Соловьев и Е.В. Шлякова выделяют в педагогике пять направлений компетенций: компетенции, связанные с социальными 
коммуникациями и работе в команде; компетенции, связанные с толерантностью к другим культурам, религиям; компетенции, определяющие уровень владения устной и письменной речью; компетенции, помогающие быстро осваивать новые технологи; компетенции, влияющие на обучаемость и желание учиться $[11$, с. 32]. Отдельно овладение информационными технологиями музыкантом как частью его интеграции в высокотехнологичную среду изучает О.В. Мхитарян, доказывающая, что профессиональное саморазвитие напрямую зависит от способности музыканта адаптироваться к информационной среде [17, с. 6].

Таким образом, исходя из вышеобозначенных позиций мы можем сделать вывод, что современное вокальное образовательное пространство должно отвечать динамике развития карьерных компетенций профессии исполнителя, тенденции всех областей современного знания к глобализации и внедрению инновационных технологий.

Рассмотрим, как данные компетенции развиваются в условиях современного вокального образования. Участие в совместных проектах и работа в команде присутствуют в практике сценического искусства и совместного исполнения вокальных номеров. Также в более широком смысле компетенции, связанные с управлением командой и принятием решений, могут быть развиты на дисциплинах по музыкальному менеджменту и бизнесу.

Способность взаимодействовать с другими культурами, с пониманием и на равных относиться к отличным от родной культуры участникам профессионального сообщества развивается при изучении этикета, истории разных стран и народов, изучении иностранных языков. В целом, иностранные языки для вокалиста в современном пространстве вокальноисполнительской культуры - это не только инструмент сценической деятельности, но и основа коммуникации и демонстрации компетенций в области грамотной устной и письменной речи.

Что касается информационных технологий, очевидно, что в современных оперных постановках активно используются мультимедийные технологии, 2D- и 3D-декорации, развиваются направления работы с технологиями звучания. И, хотя исполнитель и не обязан вникать во все тонкости сценического производства, несомненно, важны компетенции, помогающие быстро обучаться и использовать новые технологии в этом контексте.

Таким образом, роль вокалиста в современной вокально-исполнительской среде, становление его профессиональной карьеры во многом определяются способностью адаптироваться и обучаться. Далее в данной статье мы проанализируем дисциплины СанктПетербургской и Московской консерваторий, чтобы рассмотреть, как учебная программа отвечает формированию этих важных направлений компетенций обучающихся.

Современная международная вокально-исполнительская культура действительно показывает тенденции к глобализации образовательного пространства. Ориентируясь на 
интеграцию с современными международными стандартами, российское вокальное образование стремится к более тщательной проработке технологий и методик. Многие ученые отмечают этот процесс. В частности, Г. Корнетов характеризует цель современной педагогики как «множественную», «подвижную», «предельно индивидуализированную» [цит. по 8, с. 17].

Мы склонны согласиться с этими утверждениями, когда речь идет о воспитании творческого субъекта в современной вокально-исполнительской культуре. И, на наш взгляд, речь идет, с одной стороны, о роли личности в вокально-исполнительской культуре, а с другой - о влиянии открытости и доступности международного исполнительского опыта на рост и развитие молодого исполнителя.

Но при этом исполнителю недостаточно обладать базовыми компетенциями. Как мы уже сказали выше, для профессиональной деятельности необходимы не только «мягкие» компетенции, но и «твердые» профессиональные навыки, основывающиеся на единой системе знаний. Более того, эта система навыков и знаний, как и компетенции, должна отвечать «вызовам» времени в эволюции вокального искусства.

Одним из самых инновационных явлений в современном образовании, обеспечивающим приобретение учащимся единой системы знаний, является интегративный подход. Так, исследователи И.В. Яковлев и Н.О. Яковлева отмечают, что такой подход рассматривает образование в рамках разных плоскостей интеграции (внутрипредметной, личностной, внутриличностной, межпредметной) [18, с. 44-45]. Интегративный подход к обучению вокалиста способствует единству понимания теоретических и практических аспектов пения и воспитанию высокой вокально-исполнительской культуры в российских высших учебных заведениях.

Рассмотрим интегративный подход именно к вокальному искусству с точки зрения разных плоскостей интеграции. Известный петербургский вокальный педагог Т.Д. Смелкова пишет, что данная модель обеспечивает «понимание закономерностей певческого процесса и знания истории вокального искусства» [5, с. 57], а также помогает «достичь единства вокально-исполнительской практики и задач вокального образования» [5, с. 57]. Т.Д. Смелкова выдвигает теорию о том, что для модернизации современного образовательного пространства ключевым моментом является реализация таких задач, как интеграция творческого потенциала преподавателя и студента, разработка программ, сочетающих всесторонний взгляд на современную музыкальную культуру. Здесь, на наш взгляд, речь идет о межпредметной и внутрипредметной интеграции, когда подробно прорабатывается навык в рамках одной дисциплины (к примеру, сольное пение), а также создается связь между смежными дисциплинами.

Такого же подхода придерживается и исследователь И.К. Назаренко, утверждающий, 
что вопрос преемственности музыкальных традиций и знания своей истории является ключевым для формирования единой культуры, так как полное практическое познание вокального искусства невозможно без осознания опыта и нравственно-художественных ориентиров предыдущих поколения: «Без высокой музыкальной культуры не может быть и речи о правильном интонировании в широком понимании этого слова» [19, с. 409].

Мы солидарны с этим утверждением. Познание единой культуры способствует межличностному и личностному росту исполнителей в рамках российской, а затем и мировой вокально-исполнительской культуры. Это знание культуры и традиций, формирующее личные и социальные психологические и нравственные качества.

К примеру, ошибки в исполнении оперных произведений могут осуществляться, в том числе, из-за недостаточной интеграции знаний в рамках обучении оперному искусству. Так, В.П. Фомина отмечает, что сегодня оперные произведения, написанные до XIX в., часто исполняют в романтической традиции, хотя это способствует потере смысла произведения. Она настаивает на тщательном анализе исторической эпохи и определении верной интерпретационной модели для каждого оперного произведения [20, с. 134]. Таким образом, именно интегративный подход к обучению отвечает необходимости в сочетании правильного историко-культурного контекста, в том числе выражающегося в следовании вокальной традиции, и качественного вокального исполнения.

Таким образом, мы можем выделить несколько ключевых принципов интегративного подхода в вокальном образовании: взаимодействие и связь между преподаваемыми дисциплинами, обеспечивающие единую логичную и интегрированную систему знаний ученика; предоставление учащемуся возможности анализировать и сравнивать вокальные школы разных стран и эпох для различения и сохранения вокальных традиций, а также избежание культурно-исторических неточностей в исполнении (если творческая задача не предполагает иного); использование в учебном процессе разных творческих форматов обучения (мастер-классов, концертов, семинаров, творческих мастерских).

Проанализируем, действительно ли принципы интегративного и компетентностного педагогических подходов реализуются в современном российском вокальном образовании, на примере учебных планов вокальных факультетов Санкт-Петербургской консерватории имени Н.А. Римского-Корсакова и Московской государственной консерватории имени П.И. Чайковского. Для анализа мы выбираем именно эти два ведущих учебных заведения, лучших в России.

В программе обучения обеих консерваторий присутствуют дисциплины «Сольное пение», «Камерное пение», проводимые в формате индивидуальных занятий, на которых осуществляется внутрипредметная интеграция знаний через формирование индивидуальной 
манеры пения, отличающейся высокими качественными характеристиками, чистым интонированием, формированием правильной певческой позиции и дыхания, развитием персональных артистических и психологических исполнительских качеств. На наш взгляд, это именно те дисциплины, в которых способно максимально проявиться творческое соавторство студента и педагога. Так развиваются навыки пения, являющиеся первоосновой профессиональных навыков исполнителя, а также формируются компетенции самостоятельной вокальной работы.

Также в учебных планах обеих консерваторий уделено немалое внимание развитию актерского потенциала учащихся с помощью дисциплин «Актерское мастерство», «Танец», «Актерская пластика», которые в дальнейшем помогут исполнителю создавать цельные и запоминающиеся сценические образы. Дисциплина «Исполнительская практика» и практика работы в оперном театре позволяют студентам непосредственно познакомиться с реалиями будущего профессионального пути, а также проявить творческий потенциал во взаимодействии с другими студентами при создании отдельных номеров и оперных постановок. На наш взгляд, в совокупности перечисленные дисциплины по вокальному и сценическому искусству создают систему знаний, интегрирующую ученика в будущее профессиональное пространство, а также отвечают требованиям интеграции смежных сценических дисциплин.

Богатая история российского вокального образования нашла отражение в изучении таких дисциплин, как «История зарубежной музыки», «История исполнительского искусства», «История русской музыки». Сочетание данных дисциплин обусловлено историческим процессом формирования русской вокальной школы, сочетающей национальные русские традиции и зарубежные веяния. Помимо этого, исторический ракурс создает интегрированную систему знаний об искусстве и культуре разных стран, и это отвечает современной тенденции образования к глобализации.

Особое внимание нужно обратить и на то, что образовательные программы СанктПетербургской и Московской консерваторий адаптировались к тому, какие требования предъявляет карьера вокалиста к личностным и психологическим характеристикам исполнителя. Как мы уже не раз упоминали, конкуренция в сфере вокального исполнения требует от вокалиста высоких коммуникативных навыков, определенной гибкости в общении, а также понимания процессов, происходящих в мировом музыкальном менеджменте.

Так, в образовательных программах российских высших учебных заведений обязательно присутствует изучение иностранного языка и основ профессионального общения на английском языке. Кроме того, в Санкт-Петербургской консерватории изучаются дисциплины «Основы поведенческого этикета Западной Европы» и «Основы российского 
поведенческого этикета». Этикет наряду с изучением культуры и истории, на наш взгляд, формирует личность исполнителя, уважающего обычаи своей культуры и культуры той страны, в которой ему предстоит работать. Безусловно, атмосфера уважительного делового и личного общения формирует более высокий уровень вокально-исполнительской культуры. Конечно, данные дисциплины, на наш взгляд, больше отвечают принципам компетентностного подхода к педагогике, где приобретаются компетенции, развивающие социальные навыки будущего исполнителя. Кроме того, знание этикета других стран позволяет создать на сцене более точные образы, что уже относится к необходимым профессиональным «твердым навыкам».

В свою очередь, Московская консерватория включила в учебный план вокалистов дисциплину «Менеджмент в музыкальном искусстве». На наш взгляд, эта и подобные дисциплины позволяют обеспечивать общее понимание процессов, происходящих в музыкальном бизнесе, отвечают запросам на широкую квалификацию молодых специалистов. Так, к примеру, выпускники, проявившие больший интерес к кураторству, организации концертов, конкурсов и просветительских проектов, могут продолжить свой карьерный путь не в качестве исполнителя, а в качестве музыкального агента, менеджера.

Таким образом, междисциплинарное обучение значительно расширяет карьерные возможности и возможности трудоустройства. Следовательно, знание вокального маркетинга формирует также общие компетенции исполнителя в профессиональной карьере и может стать полноценным «твердым» навыком специалиста.

Таким образом, в ходе обучения российских вокалистов в высших учебных заведениях реализуются следующие дидактические принципы: получение комплекса практических знаний в сфере вокально-исполнительской подготовки, включающего самостоятельную работу студентов; комбинирование внутриклассной учебной деятельности с внеаудиторной исполнительской практикой; преподавание вокальных дисциплин, обеспечивающих связь теории и практики вокального искусства, а также интеграцию междисциплинарных знаний и изучение межпредметных связей. Такое сочетание разных форматов обучения отвечает одному из выделенных нами принципов интегративного подхода к обучению вокальному искусству.

На примере Санкт-Петербургской и Московской консерваторий мы рассмотрели возможность реализации интегративного подхода, создающего единую систему знаний, компетентностного подхода, подкрепляющего эту систему соответствующими навыками, расширяющими музыкально-творческие и общекультурные ресурсы исполнителя в мировом вокально-образовательном пространстве.

Вместе с тем считаем необходимым отметить, что в программах российских 
консерваторий, в отличие от подобных ученых заведений в Европе, отсутствуют занятия по дикции при пении на разных языках. Некоторые исследователи российского образования, к примеру Т.Д. Смелкова, обращают внимание на то, что «отсутствие занятий по артикуляции на разных языках влияет и на практику обучения иностранных студентов в России» [5, с. 58]. Так, при изучении русского и западноевропейского репертуара особые трудности без соответствующих занятий испытывают студенты из Кореи и Китая по причине сильно отличающегося произношения в их родном языке. Кроме того, в российских консерваториях не практикуется подготовка по более узким специализациям, как это реализуется, к примеру, в программах по изучению барочного вокального искусства в Германии.

\section{Заключение}

На основе анализа работ известных ученых и вокальных педагогов-практиков мы обозначили вокально-исполнительскую культуру как сочетание национальных культурноисторических исполнительских традиций с профессиональным уровнем певцов, их личностной интерпретацией произведений. Было рассмотрено, как данные спецификации находят свое отражение в рабочих программах двух ведущих консерваторий России.

Кроме того, мы кратко охарактеризовали современные понятия на музыкальном «рынке труда» - hard skills (англ. «жесткие навыки») и soft skills (англ. «мягкие навыки») - и показали, как развитию базовых профессиональных «жестких навыков» способствует применение интеграционного подхода к вокальному образованию, включающее в себя внутрипредметную интеграцию, углубляющую и корректирующую навыки в конкретном сегменте (пример - сольное пение); межпредметную, создающую систему знаний в смежных дисциплинах; личностную и внутриличностную, обеспечивающую психологическую адаптацию исполнителя при сольном исполнении и в рамках взаимодействия в творческом коллективе.

Однако «мягкие» навыки обеспечивают скорость принятия решений, умение плодотворно сотрудничать в коллективе с разными культурами и нациями, быть толерантным, грамотно и аргументированно отстаивать свою творческую позицию, использовать инновационные певческие технологии, психологически адаптироваться к поставленным исполнительским задачам, демонстрировать способности к дальнейшему обучению и самосовершенствованию. Это те компетенции, которые сложнее измерить, нежели конкретные профессиональные навыки, однако они являются ключевым фактором успеха молодого специалиста в дальнейшей творческой деятельности.

Подчеркнем, что многопрофильное вокальное образование способствует качественному формированию вокально-исполнительской культуры. В этом процессе педагог и его воспитанник выступают в творческом соавторстве в парадигме уважения к культуре, 
истории и личности. При этом акцент в теории современного вокального образования смещается с личности педагога как «образца» к уникальности личности будущего исполнителя, а «знаниевый» педагогический подход замещается «компетентностным». Таким путем развиваются навык более самостоятельного и комплексного мышления студента, критическое и мотивированное отношение к будущей профессии.

В учебных программах Санкт-Петербургской и Московской консерваторий присутствуют дисциплины, развивающие как вокальные данные исполнителя, так и способствующие развитию его сценических качеств. В свою очередь, интегративный подход реализуется через дисциплины, посвященные истории и культуре разных стран, а также изучению специфики национальных этикетов. Внимание уделяется, в том числе, изучению иностранных языков, а также общему пониманию специфики музыкального бизнеса (дисциплина «Менеджмент в музыкальном искусстве»). Мы определили, как в различных музыкальных дисциплинах могут одновременно присутствовать и интеграционный, и компетентностный подходы к учебному процессу вокального класса, что обеспечивает формирование комплексной системы знаний и сопутствующих компетенций, целями которых в конечном итоге являются конкурентоспособность вокалиста в вокально-исполнительском пространстве мировой культуры, понимание традиций разных вокальных школ и сохранение их богатого наследия.

Мы показали на примере учебных программ двух ведущих консерваторий России возможности использования компетентностного и интеграционного подходов в формировании вокально-исполнительской культуры студентов. Есть все основания полагать, что дисциплины Московской и Санкт-Петербургской консерваторий в значительной мере отвечают проблеме формирования целостной вокально-исполнительской культуры молодых специалистов. У них складывается система знаний, позволяющая не только развивать исполнительские технологии, но и понимать процессы развития различных вокальных стилей и национальных школ. Кроме того, актуализируются коммуникативные навыки взаимодействия с членами профессионального сообщества, расширение сценической практики, возможности деловых взаимоотношений в музыкальном бизнесе, т.е. создаются условия для качественного улучшения вокально-исполнительской культуры молодых специалистов.

\section{Список литературы}

1. Полякова Н.Ю., Абрамович Ю.Б. Роль образования для достижения успеха в жизни // 
Эпоха науки. 2020. № 24. С. 316-320.

2. Шатилов А.Б., Заугаров В.В. Академическая мобильность как фактор «Мягкой силы» российской федерации: пути совершенствования // Власть. 2019. № 6. С. 30-34.

3. Чжэнь Н. Сущность и структурно-содержательные характеристики понятия «Вокальная культура младшего школьника» // Инновационная наука. 2021. № 7. С. 129-135.

4. Сенцова А.Г., Полищук Л.Л. Вокальная культура как психологический феномен: к истории вопроса // Азимут научных исследований: педагогика и психология. Тольятти. 2018. T.7. № 3 (24). C. 377-380.

5. Смелкова Т.Д. Вокально-исполнительская культура в современном образовательном пространстве // Universum: Вестник Герценовского университета. 2014. № 1. С. 56-60.

6. Густякова Д.Ю. Опера в фокусе массовой культуры: парадоксы репрезентации классики Большим театром России // Ярославский педагогический вестник. 2017. № 3. С. 274280 .

7. Экнадиосов В.С. Учебный оперный спектакль и его роль в формировании певцапрофессионала // Южно-Российский музыкальный альманах. 2015. № 2 (19). С. 10-14.

8. Антоненко Н. Некоторые Актуальные вопросы вокального образования в контексте современного исполнительского искусства // Южно-Российский музыкальный альманах. 2014. № 4 (17). C. 17-21.

9. Арчажникова Л.Г. Профессия - учитель музыки. М.: Просвещение, 1984. 110 с.

10. Курдина Е.С. Формирование учебной самостоятельной деятельности вокалистов в дополнительном музыкальном образовании // Педагогическое образование в России. 2014. № 10. С. 114-119.

11. Федоров А.Э., Метелев С.Е., Соловьев А.А., Шлякова Е.В. Компетентностный подход в образовательном процессе: монография. Омск: Изд-во ООО «Омскбланкиздат», 2012. 210 с. 12. Ковальчук Н.Н., Ставер Т.Г. Реализация компетентностного подхода в системе высшего образования (теоретический аспект) // МНКО. 2018. № 2 (69). С. 409-411.

13. Иванов Д.А., Митрофанов К.Г., Соколова О.В. Компетентностный подход в образовании. Проблемы, понятия, инструментарий: учебно-методическое пособие. М.: АПКиПРО, 2003. $101 \mathrm{c.}$

14. Коган Е.Я. Компетентностный подход и новое качество образования // Современные подходы к компетентностно-ориентированному образованию: материалы семинара / Под ред. А.В. Великановой. Самара: Профи, 2001. С. 28-32.

15. Останина С.А., Птицына Е.В. Компетентностный подход к обучению студентов вуза в условиях реализации образовательных стандартов третьего поколения // Мир науки. Педагогика и психология. 2019. № 5 (7). С. 1-12. 
16. Зимняя И.А. Ключевые компетенции - новая парадигма результата образования // Эксперимент и инновации в школе. 2009. № 2. С. 7-14.

17. Мхитарян О.В. Информационная культура музыканта как условие готовности к профессиональному саморазвитию // Культура: теория и практика. 2014. № 2. С. 6.

18. Яковлев Е.В., Яковлева Н.О. Педагогическое исследование: содержание и представление результатов. Челябинск: Изд-во РБИУ, 2010. 317 с.

19. Назаренко И. К. Искусство пения. М.: Музыка, 1968. 624 с.

20. Фомина В.П. Раннебарочная вокально-интерпретационная модель как необходимый атрибут профессионального образования вокалиста: сущность и структура // Музыкальное искусство и образование. 2015. № 4 (12). С. 133-139. 